Vesa K. Kontinen BM, Eeva-Liisa Maunuksela MD PhD, Johanna Sarvela MD

\title{
Premedication with sublingual triazolam compared with oral diazepam
}

The clinical effects of a new administration form of triazolam, $0.2 \mathrm{mg}$ sublingual (sl) tablet, were compared with those of a $10 \mathrm{mg}$ tablet of diazepam in a double-blind study, in $100 \mathrm{ASA}$ I-II patients scheduled for opthalmic surgery under local anaesthesia. The sedative and anxiolytic effects of the study drugs were followed at 15 min intervals by plotting the patient's assessments on a visual analogue scale and by a trained observer. The onset of sedative and anxiolytic effect was similar. At 75 min after premedication and after the operation triazolam 0.2 $\mathrm{mg}$ caused deeper sedation than diazepam $10 \mathrm{mg}$ according to the observer $(P<0.001, P<0.01)$ and according to the patient $(P<0.01, P<0.05)$. Ten patients $(20 \%)$ in the triazolam group and one in the diazepam group were assessed to be too sedated during the operation. All these patients were $61-70 \mathrm{yr}$ old. The study drugs resulted in equal reduction of anxiety during the preoperative period. Both premedicants provided good patient comfort but caused total amnesia only to one patient in each group. Neither caused any severe cardiorespiratory or other side effects. It is concluded that $0.2 \mathrm{mg}$ triazolam sl produces deeper sedation than $10 \mathrm{mg}$ oral diazepam. For elderly patients this dose is excessive for intraocular surgery.

Les effets d'une nouvelle présentation de triazolam $0,2 \mathrm{mg} \mathrm{sub}$ lingual (sl) sont comparés à ceux de la tablette de diazépam $10 \mathrm{mg}$ dans une étude à double aveugle chez 100 patients $A S A$ 1-2 programmés pour une chirurgie ophthalmique sous anesthésie locale. Les propriétés sédatives et anxiolytiques des médicaments à l'étude sont cotés aux 15 min par le malade et un observateur compétent sur une échelle visuelle analogue. Le début de l'activité sédative et anxiolytique ne differe pas pour

\section{Key words}

PREMEDICATION: benzodiazepines, diazepam, triazolam; SURGERY: ophthalmological.

From the Department of Anaesthesia, Helsinki University Eye Hospital, Haartmaninkatu 4 C, SF-00290 Helsinki, Finland. Address correspondence to: Dr. Vesa Kontinen, Nallenpolku 2 C 40, SF-02110 ESPOO.

Accepted for publication 10th June, 1993. les deux drogues. A 75 min après la prémédication et après la chirurgie, le triazolam $0,2 \mathrm{mg}$ produit une sédation plus profonde que le diazépam $10 \mathrm{mg}$ d'après l'observateur, $(P<0,001$, $P<0,01)$ et d'après le patient $(P<0,01, P<0,05)$. On note une sédation exagérée chez dix patients (20\%) du groupe triazolam et un du groupe diazepam. Tous ces patients sont agés de 61 à 70 ans. Les drogues étudiées produisent une réduction égale de l'anxiété préopératoire. Les malades sont comfortables sous les deux prémédications. L'amnésie totale ne survient que pour un seul malade dans chaque groupe. On ne note pas d'effets cardiorespiratoires importants. Nous concluons que le triazolam $0,2 \mathrm{mg}$ sl produit une sédation plus profonde que diazépam $10 \mathrm{mg}$ po. Pour les patients plus âgés, cette posologie est excessive en chirurgie oculaire.

One of the aims of premedication given before local anaesthesia is to relieve the patient's anxiety. Because of their anxiolytic, sedative, amnestic and relaxing properties, oral benzodiazepines are commonly used for premedication, diazepam probably being most often used.' An optimal premedicant should have a rapid onset of action, sufficient sedative and anxiolytic properties and it should not endanger ventilation or circulation. During operations which require the patient's cooperation excessive sedation may cause problems. ${ }^{2}$ In ophthalmic surgery with local anaesthesia head movements of an over sedated patient, snoring or dreaming are disturbing and might even risk the outcome of the operation.

Oral administration of the premedication is comfortable and practical. Some water must be taken with a tablet and according to $\mathrm{Hey}^{3}$ the patient should remain in an upright position for some minutes after swallowing the tablet as the tablet taken while lying may not be absorbed properly. The reported effects of oral triazolam as premedication have been variable. ${ }^{4-6}$ Theoretically, sublingual tablets offer more even absorption with less interindividual variation and, therefore, a more reliable effect. Accordingly, $0.2 \mathrm{mg}$ triazolam $s l$ was shown to produce blood concentrations equal to $0.25 \mathrm{mg}$ po (Dumozolam ${ }^{\circledR}$ registration documentation, Copenhagen 1990). 
The purpose of this study was to compare the clinical effects of the new administration form of triazolam, a $0.2 \mathrm{mg}$ sublingual tablet, with a standard $10 \mathrm{mg}$ tablet of diazepam as premedication for ophthalmic surgery performed under local anaesthesia.

\section{Methods}

The goal of premedication was to relax the patient sufficiently to (1) allow him to tolerate the injection of local anaesthesia without disturbing movements, (2) to allow him to lie still during the ophthalmic surgery but remain cooperative, (3) to make the experience in the operating room as pleasant as possible for the patient.

\section{Pilot study}

To test the sedative efficacy of the new sublingual formulation of triazolam we did an open pilot study comparing a standard $10 \mathrm{mg}$ diazepam tablet with 0.2 and $0.4 \mathrm{mg}$ triazolam $s l$ tablets and without premedication, with five patients in each group. All patients with 0.4 $\mathrm{mg} s l$ triazolam were excessively sedated up to the point that they did not respond to verbal or mild tactile stimulation. Vital signs remained stable. Patients with $0.2 \mathrm{mg}$ of triazolam and $10 \mathrm{mg}$ of diazepam were sedated but remained alert and cooperative.

\section{Double-blind study}

One hundred patients, 18 to $70 \mathrm{yr}$ of age, male and female, admitted for elective intraocular or periocular surgery in the Helsinki University Eye Hospital, were studied. The patients were ASA class I or II. Informed consent according to the Helsinki II declaration was obtained. Patients who were pregnant, breast-feeding, suffering from myasthenia gravis, allergic to benzodiazepines or chronically using hypnotics or sedatives were excluded. The study was a double-blind, non-cross-over parallel group arrangement, and has been accepted by the Ethics Committee of the hospital.

The study drugs were supplied in sealed, numbered envelopes containing either a. $s l$ tablet of triazolam 0.2 mg (Dumozolam ${ }^{\circledR}$, Dumex Ltd., Denmark) and a placebo tablet or a tablet of diazepam $10 \mathrm{mg}$ (Stesolid ${ }^{\circledR}$, Dumex Ltd., Denmark) and a placebo $s$ t tablet. The placebo preparations supplied by Dumex Ltd., Denmark were identical in appearance with the study drugs. The study tablet was given with a small amount of water and immediately after it was swallowed, the $s l$ tablet was dropped under the patient's tongue.

The day before surgery the patients were visited by one of the anaesthetists (E.-L.M. or J.S.) and the study plan and the visual analogue scale (VAS) used in the assessments were explained. If the patient could use the scale, physical examination and assessment of anxiety

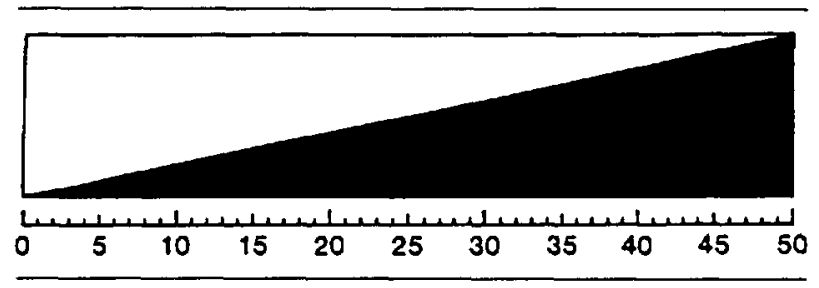

FIGURE I Red and white $50 \mathrm{~cm}$ long and $10 \mathrm{~cm}$ high visual analogue scale (VAS) used in the study. ${ }^{8}$

were performed by the anaesthetists. The patient expressed his preoperative anxiety on the VAS.

Approximately one hour before the operation the patients were transported to the recovery room. Continuous monitoring of ECG and oxygen saturation was started (Cardiocap, Datex, Helsinki, Finland or Dinamap, Criticon, Tampa, Florida, USA and Satlite, Datex, Helsinki, Finland). Before giving the study drug, and every $15 \mathrm{~min}$ thereafter, blood pressure was measured and sedation and anxiety were assessed by the observer and by the patient. The sedation was assessed using the following five-point scale: $0=$ completely awake, 1 = awake, but drowsy, $2=$ asleep, but responds easily to verbal command, 3 $=$ asleep, but responds to tactile stimulus, $4=$ asleep, does not respond to any gentle stimulus. Anxiety was assessed by the observer taking into account the measured physical signs, mimic, position and behaviour of the patient and it was scored with a four-point scale: $0=$ fully relaxed, $1=$ minor, $2=$ moderate and $3=$ severe anxiety. One of the two designated research nurses or one of the researchers (V.K.) assessed the patient throughout the observation period.

It was realized that there is a bias in assessing the sedation and anxiety by an observer. Therefore, the patient was asked to do his own assessment of sedation and anxiety using the VAS. The scale was a $50 \mathrm{~cm}$ long and $10 \mathrm{~cm}$ high card, diagonally divided to a white and a bright red triangle (Figure 1). The centimeter scale was on the rear side of the card. ${ }^{7,8}$ The extremes were marked "no sedation/anxiety" at the white end and "sedation/ anxiety as bad as ever can be" at the red end. ${ }^{9}$

After a minimum of $45 \mathrm{~min}$ from administration of the study drugs, peribulbar anaesthesia for intraocular surgery was administered by one of the two anaesthetists participating in the study, with the usual methods of the department and using similar volumes of $1.5 \%$ etidocaine. The infiltration of local anaesthesia for lid or lachrymal canal surgery was performed by the surgeon. During injection of local anaesthesia the adequacy of premedication was evaluated by the anaesthetists and during the operation by the anaesthesia nurse after consulting with the operating surgeon. The following scale was used: (1) not adequately sedated $=$ tension of limbs and trunk, dis- 
TABLE I Demographic data and type of operation (mean \pm SD, number of patients, range in parenthesis). The male/female ratio is different between the groups, $P<0.01$.

\begin{tabular}{lll}
\hline & $\begin{array}{l}\text { Triazolam } \\
n=50\end{array}$ & $\begin{array}{l}\text { Diazepam } \\
n=50\end{array}$ \\
\hline Age, yr & $59 \pm 10$ & $56 \pm 10$ \\
& $(41-70)$ & $(31-70)$ \\
Male/female & $22 / 28$ & $37 / 13$ \\
Weight, $\mathrm{kg}$ & $72.3 \pm 13.0$ & $75.0 \pm 14.4$ \\
& $(50-108)$ & $(50-116)$ \\
Height, $\mathrm{cm}$ & $166 \pm 11$ & $170 \pm 9$ \\
& $(126-182)$ & $(141-186)$ \\
Body Mass Index, $\mathrm{kg} \cdot \mathrm{m}^{-2}$ & $26 \pm 4$ & $26 \pm 5$ \\
& $(19-36)$ & $(20-43)$ \\
Duration of surgery, $\mathrm{min}$ & $35 \pm 16$ & $36 \pm 19$ \\
& $(5-80)$ & $(7-112)$ \\
Type of operation & & \\
- intraocular & 37 & 38 \\
- extraocular & 13 & 12 \\
\hline
\end{tabular}

turbing movements, irrelevant questions and complaints other than pain, (2) adequately sedated = relaxed but awake, able to remember and follow orders, maintains the airway without snoring, or (3) too sedated $=$ asleep and snoring or waking up with sudden movement, does not remember where he is or follow orders.

After the operation but before the patient was sent back to the ward, he was asked to evaluate the experience in the operating room with a scale: very pleasant, pleasant, satisfactory, unpleasant. He was also asked if he had amnesia about the injection of local anaesthesia and/ or operation. In addition the patient evaluated his present sedation and anxiety. The same observer who had assessed him before the operation assessed the postoperative sedation and anxiety. Next morning the ward was called to learn about any unusual reactions or side effects.

\section{Statistical analysis}

Differences in related characteristics between the study groups were examined for statistical significance using chi-square test for discrete variables and $t$ test for continuous variables. Two-way analysis of variance was used to test the difference in the assessments between the observers. All tests of significance were two-tailed, $P$-value of 0.05 was accepted as the limit for significance.

\section{Results}

The study groups were comparable for age, weight, height and body mass index, but the ratio male/female differed (Table I). The day before operation and prior to premedication there were no differences between the study groups in heart rate, blood pressure, capillary oxygen saturation, anxiety or sedation. The mean time from the

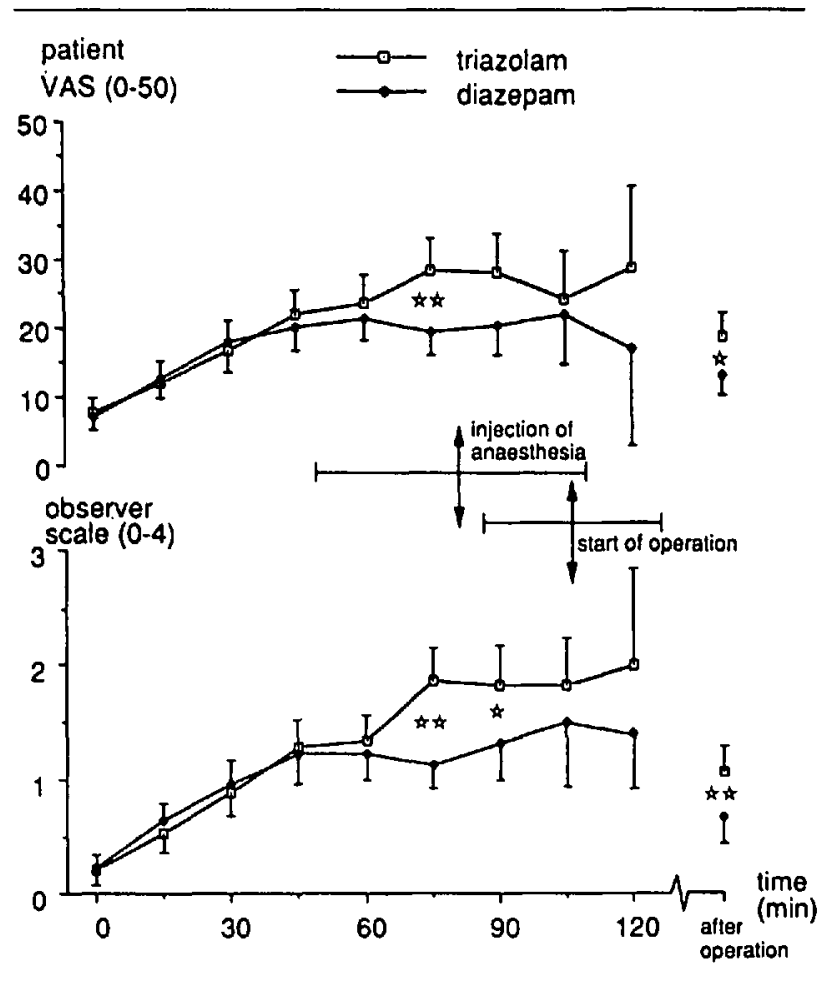

FIGURE 2 Sedation following $0.2 \mathrm{mg}$ of $\mathrm{s} /$ triazolam and $10 \mathrm{mg}$ of oral diazepam assessed by the patient using VAS and by the observer with a rating scale of $0-4$ (mean, $95 \%$ c.l.). The injection of local anaesthesia and the start of operation indicated with arrows (mean, SD). Statistically significant differences between the treatment groups are indicated with $(P<0.05)$ and $(P<0.01)$.

administration of premedication until injection of local anaesthesia was $80 \pm 4$ and $77 \pm 4 \mathrm{~min}$ and from the injection of local anaesthesia until start of the surgery $32 \pm 3$ and $34 \pm 4 \mathrm{~min}$, in the triazolam and diazepam groups, respectively.

At 75 and $90 \mathrm{~min}$, and after the operation, triazolam caused deeper sedation than diazepam according to the observer $(P<0.001, P<0.05, P<0.01)$ and at 75 min and after the operation according to the patient $(P$ $<0.01, P<0.05$ ) (Figure 2). Both study drugs resulted in equal reduction of anxiety during the preoperative period (Figure 2).

There was good correlation between the observer's assessment and the patient's evaluation of both sedation and anxiety in the operation room. The correlation coefficients were between $0.35-0.71$ in sedation scores, $0.30-0.62$ in anxiety scores during the first $90 \mathrm{~min}$ after premedication and the respective $P$-values between $0.0001-0.0003$ and $0.0001-0.0051$, respectively. After 90 $\mathrm{min}$, the number of patients was too small for correlation analysis. The anxiety ratings given the day before operation differed: the observers rated the anxiety relatively 
TABLE II Assessments of adequacy of sedation during injection of local anaesthesia and during operation (number of patients, $\%$ in parenthesis)

\begin{tabular}{|c|c|c|c|c|}
\hline & \multicolumn{2}{|c|}{$\begin{array}{l}\text { During injection of local } \\
\text { anaésthesia }\end{array}$} & \multicolumn{2}{|c|}{ During operation } \\
\hline & $\begin{array}{l}\text { Triazolam } \\
n=50\end{array}$ & $\begin{array}{l}\text { Diazepam } \\
n=50\end{array}$ & $\begin{array}{l}\text { Triazolam } \\
n=49\end{array}$ & $\begin{array}{l}\text { Diazepam } \\
n=48\end{array}$ \\
\hline Not adequately sedated & $7(14)$ & $4(8)$ & $4(8)$ & $2(4)$ \\
\hline Adequately sedated & $42(84)$ & $46(92)$ & $35(72)$ & $45(94)$ \\
\hline Too sedated & I (2) & $0(0)$ & $10(20)$ & $1(2)$ \\
\hline$P$ & \multicolumn{2}{|c|}{ NS } & \multicolumn{2}{|c|}{0.05} \\
\hline
\end{tabular}

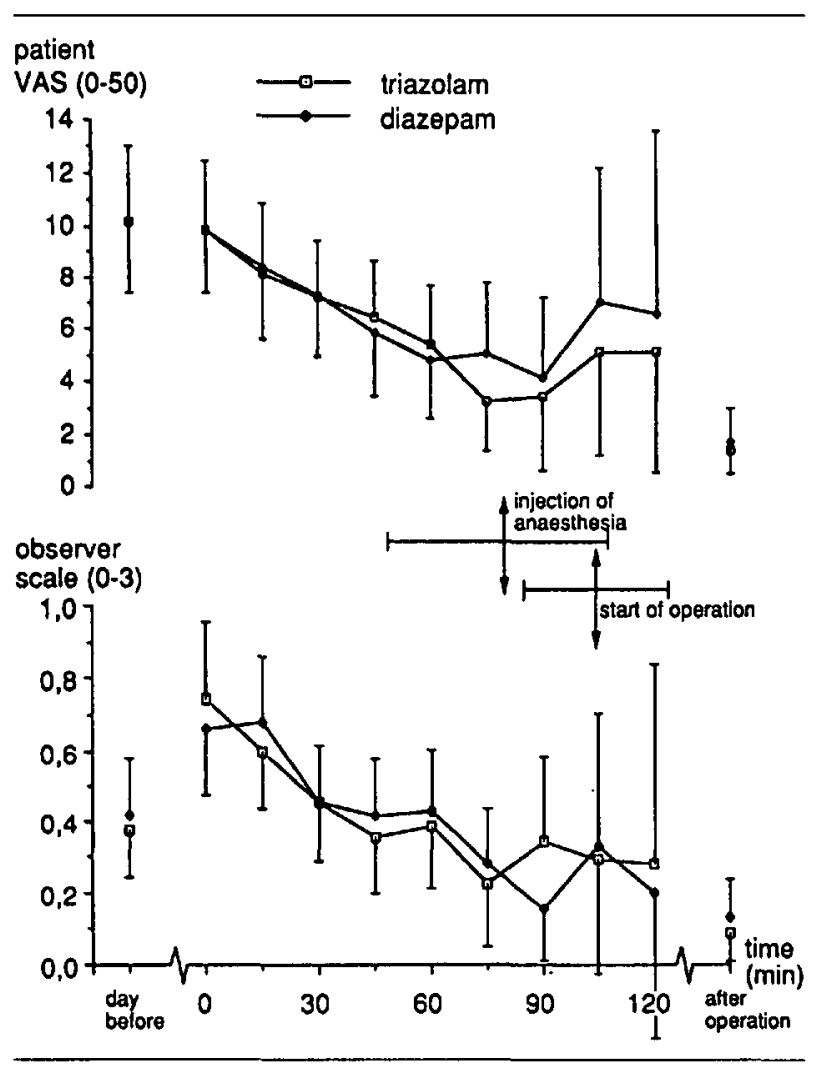

FIGURE 3 Anxiety the day before operation and after premedication with $0.2 \mathrm{mg}$ of $s /$ triazolam and $10 \mathrm{mg}$ of oral diazepam assessed by the patient using VAS and by the observer with a rating scale of $0-3$ (mean, 95\% c.l.). The injection of local anaesthesia and the start of operation indicated with arrows (mean, SD). There were no statistically significant differences between the treatment groups.

lower than the patients (Figures 2 and 3). The patients of the two study groups were evenly distributed among the three observers and between the two anaesthetists. There were no differences in the sedation assessments at 75 and $90 \mathrm{~min}$ after premedication between the observers when tested with two-way analysis of variance.

Evaluation of the efficacy of premedication during the injection of local anaesthesia and during the operation
TABLE III Patient's evaluation of the experience in the operating room (number of patients, $\%$ in parenthesis)

\begin{tabular}{lcc}
\hline & $\begin{array}{l}\text { Triazolam } \\
n=45\end{array}$ & $\begin{array}{l}\text { Diazepam } \\
n=45\end{array}$ \\
\hline Very pleasant & $17(38)$ & $14(31)$ \\
Pleasant & $23(51)$ & $23(51)$ \\
Satisfactory & $4(9)$ & $7(16)$ \\
Unpleasant & $0(0)$ & $0(0)$ \\
Total amnesia & $1(2)$ & $1(2)$ \\
$P$ & \multicolumn{2}{c}{ NS } \\
\cline { 2 - 3 }$P$
\end{tabular}

is shown in Table II. All patients who were assessed to be too sedated during the operation were 61-70 years old (mean $67 \pm 2.8$ ). There were no differences in their weight, body mass index or sex compared with the rest of the patients. All had an intraocular operation. One of the patients was assessed to be too sedated already during the injection of the local anaesthetic, another was not adequately sedated at the injection of local anaesthetic, but was too sedated during the operation.

During the operation four patients in the triazolam group and two in the diazepam group were assessed by the operating surgeon to be inadequately sedated. Supplementary benzodiazepine (diazepam or midazolam) was given to these patients and to one patient in the triazolam group, who was assessed to be too sedated. General anaesthesia was administered to three patients because of inadequate local anaesthesia; two were in the diazepam group and one in the triazolam group. All these patients were excluded from the postoperative assessments. Fentanyl $0.05 \mathrm{mg} \dot{w}$ was given to five patients for pain.

There were no differences between the study groups (Table III) in the patient's evaluations of the experience in the operating room, recorded before transportation to the ward.

The mean duration of surgery did not differ between the study groups (Table I). Because of the general arrangement, the patients stayed in the recovery room an 
average of $30 \pm 4 \mathrm{~min}$ after the operation. There were no side effects to prolong the stay of any patient and there were no differences between the study groups.

There were no differences between the study drugs in heart rate, blood pressure or capillary oxygen saturation. The patients suffered no clinically important cardiovascular effects or desaturation under $92 \%$, except for one patient in the diazepam group, whose capillary oxygen saturation was $89-92 \%$ during the 45 min period before operation with the sedation score of 1 . No side effects like rash, dizziness, headache, nausea and vomiting were observed after administration of the study drugs.

\section{Discussion}

Triazolam has been well studied as an hypnotic, but not when given for premedication. The sublingual administration route has been studied only once. ${ }^{10}$ The new sublingual preparation used in the present study results in more reliable absorption and higher blood concentrations than ingested triazolam. A dose of $0.2 \mathrm{mg} s l$ corresponds to $0.25 \mathrm{mg}$ by the oral route (Dumozolam ${ }^{\circledR}$ registration documentation, Copenhagen 1990). Because individual responses to benzodiazepines are known to vary widely, we did not try to relate the studied benzodiazepine doses to body weight but the commercial tablets were used. However, very old and ill patients were excluded.

It is normal in Finland that patients coming for surgery, either under general or local anaesthesia, receive sedative premedication on the ward. During recent years oral benzodiazepines have gained popularity over parenteral opioids. The sedative and relaxing properties are thought to aid administration of anaesthesia. The amnestic effect covers minor inconveniences and makes the memory of the operating room visit more positive to the patient. In this study it was probably due to the partial amnesia that the patients' comments about their experience in the operating room were so positive. However, only two patients had total amnesia of the procedures. Only those patients staying in the hospital overnight were selected to participate in this study.

\section{Patients}

The patients were well divided in the study groups according to other variables but sex. Because of the difference in the number of male and female patients in the study groups the results were tested by sex which was found not to interfere with the results.

\section{Onset and duration of action}

Studies assessing triazolam as an hypnotic claimed that it had a rapid onset of effect, ${ }^{11}$ which would make it useful for premedication. In the present study sedation developed in 60-90 $\mathrm{min}$, which was similar to diazepam.
Many earlier studies involved only a single assessment at a fixed time so that the maximum effect as well as the time to onset of effect might have been missed. $4,12,13$ There is controversy about the duration of action of triazolam. It has been used successfully as a premedicant for day case surgery. ${ }^{5}$ On the other hand a $0.25 \mathrm{mg}$ dose has been claimed to have a sedative effect which lasted longer than that of diazepam $10 \mathrm{mg}$ or midazolam 15 mg. ${ }^{6}$ In the present study, at about three hours after administration of premedication the effect of triazolam 0.2 mg was still greater than that of diazepam $10 \mathrm{mg}$. The end point of sedation was not assessed. There are also studies where the sedative effects of 0.125 or $0.25 \mathrm{mg}$ of triazolam were not distinguished from placebo. ${ }^{4}$ These differences might be due to different patient populations, cultural and environmental factors as well as different assessment times and sensitivity of assessments.

\section{Sedation}

The sedative potency of triazolam is probably generally underestimated. In the present study $s l$ triazolam $0.2 \mathrm{mg}$ produced more sedation than oral diazepam $10 \mathrm{mg}$. Typically, for ophthalmic surgery, we had many elderly patients in the study groups. Sensitivity to benzodiazepines is known to increase with age. ${ }^{11,14,15}$ In other types of surgery, a sleeping patient might not disturb the outcome as much as in microscopic ophthalmic procedures. In the present study all patients considered to be too sedated were relatively old and had intraocular surgery. For this age group the dose of preoperative benzodiazepine should be reduced: triazolam $0.2 \mathrm{mg}$ was excessive.

\section{Anxiolysis}

It is difficult to assess the anxiolytic effect of premedication. Other factors such as preoperative information and assurance and the attitude of the operating room team must influence the level of anxiety. For the observer, sedation cannot always be distinguished from anxiolysis. However, we believe that the patient is able to distinguish tiredness from fear and assess them separately. Baughman et al. did not find any anxiolysis with diazepam 5 or $10 \mathrm{mg}$ or triazolam 0.125 or $0.25 \mathrm{mg} .{ }^{4}$ Pinnock reported anxiolysis after diazepam $10 \mathrm{mg}$ but could not distinguish triazolam from placebo. ${ }^{16}$ In the present study sl triazolam $0.2 \mathrm{mg}$ produced similar anxiolysis as oral diazepam $10 \mathrm{mg}$.

The anxiolysis seemed to decrease after $90 \mathrm{~min}$. Normally at this time the patients would have proceeded to the operation. Therefore, this might be a normal reaction to an unexpected delay in the operating schedule and not a sign of the end of the drug effect. At this time there was only a minor decrease in sedation in the diazepam group but none in the triazolam group. 


\section{Cardiorespiratory and side effects}

Neither of the premedicants caused clinically important cardiorespiratory reactions. The only patient with a low $\mathrm{SpO}_{2}$ was not heavily sedated. Unfortunately there is no explanation for the low values found over a long period in the patient records. The sedation scores point rather to mild sedation and possibly a cold periphery resulting in this artifact. Side effects such as skin rash, dizziness, headache, nausea and vomiting were not seen during the operation or reported from the floor. Excessive sedation was discussed earlier.

In summary, we found that triazolam $s l 0.2 \mathrm{mg}$ had a similar onset of effect as $10 \mathrm{mg}$ oral diazepam and an anxiolytic effect of the same order. However, the sedative effect of triazolam was greater than that of diazepam. Twenty percent of the patients, all over $61 \mathrm{yr}$ of age, were considered to be too sedated for intraocular surgery. Both premedications provided good patient comfort but total amnesia only in a few. Neither caused cardiovascular or other side effects.

\section{Acknowledgements}

We wish to thank Dumex Ltd., Denmark for producing and randomizing the study drugs. The statistical analysis was done by Mr. Jorma Torppa M.Sc. Our gratitude is due to Ms. Eva Ahlström Bengs, M.Sc. for her excellent cooperation in managing the patient data and facilitating the production of the manuscript. We are grateful for the help of the recovery room and especially for Ms. Riitta Lindelöf R.N., for her invaluable assistance in the assessments.

\section{References}

1 Kennedy $S K$, Longnecker DE. History and principles of anesthesiology. In: Gilman AG, Rall TW, Nies AS, Taylor P (Eds.). Goodman and Gilman's the Pharmacological Basis of Therapeutics, 6th ed. New York: Pergamon Press, Inc., 1991; 269-84.

2 White PF. Pharmacologic and clinical aspects of preoperative medication. Anesth Analg 1986; 65: 963-74.

3 Hey $H$, Sørensen $K$, Jorgensen FB, Hasselbalch, Wamberg $T$. Kapslers og tabletters passagetid gennem esophagus. Ugeskr. f. Laeger 1983; 145: 2432-5.

4 Baughman VL, Becker GL, Ryan CM, Glaser M, Abenstein $J P$. Effectiveness of triazolam, diazepam, and placebo as preanesthetic medications. Anesthesiology 1989; 71: 196-200.

5 Riefkohl $R$, Kosanin $R$. Experience with triazolam as a preoperative sedative for outpatient surgery under local anesthesia. Aesthetic Plast Surg 1984; 8: 155-7.

6 Forrest P, Galletly DC, Yee P. Placebo controlled comparison of midazolam, triazolam and diazepam as oral premedicants for outpatient anaesthesia. Anaesth Intensive Care 1987; 15: 296-304.
7 Tigerstedt I, Tammisto T. A modified visual analogue scale (VAS) for evaluation of pain intensity during immediate postoperative recovery. Schmerz Pain Doleur 1988; 9 : 27-31.

8 Maunuksela E-L, Olkkola KT, Korpela $R$. Measurement of pain in children with self-reporting and behavioral assessment. Clin Pharmacol Ther 1987; 42: 137-41.

9 Aitken RC. Measurement of feelings using visual analogue scale. Proceedings of the Royal Society of Medicine 1969; 62: 939-93.

10 Manani $G$, Blasone $R$, Cirillo $L$, et al. La sedazione nella piccola chirurgia ambulatoriale del cavo orale: il triazolam sublinguale. Giornale di Anestesia Stomatologica 1989; 4: 7-17.

11 Pakes GE, Brogden RN, Heel RC. Speight TM, Avery GS. Triazolam: a review of its pharmacological properties and therapeutic efficacy in patients with insomnia. Drugs 1981; 22: 81-110.

12 Male CG, Lim YT, Male M, Stewart JM, Gibbs JM. Comparison of three benzodiazepines for oral premedication in minor gynaecological surgery. $\mathrm{Br} \mathrm{J}$ Anaesth 1980; 52: 429-36.

13 Male CG, Johnson $H D$. Oral benzodiazepine premedication in minor gynaecological surgery. $\mathrm{Br} \mathrm{J}$ Anaesth 1984; 56: 499-507.

14 Greenblatt DJ, Divoll M, Abernethy DR, Moschitto $L J$, Smith RB, Shader RI. Reduced clearance of triazolam in old age: relation to antipyrine oxidizing capacity. $\mathrm{Br} \mathrm{J} C$ lin Pharmacol 1983; 15: 303-9.

15 Nikaido AM, Ellinwood EH Jr, Heatherly DG, Gupta SK. Age-related increase in CNS sensitivity to benzodiazepines as assessed by task difficulty. Psychopharmacology (Berl) 1990; 100: 90-7.

16 Pinnock CA, Fell D, Hunt PCW, Miller R, Smith G. A comparison of triazolam and diazepam as premedication agents for minor gynaecological surgery. Anaesthesia 1985; 40: 324-8. 